\title{
Flora da Bahia: Siphonocladaceae
}

Aigara Miranda Alves ${ }^{1 *}$, Lísia Mônica de Souza Gestinari² \& Carlos Wallace do Nascimento Moura ${ }^{1}$

${ }^{1}$ Laboratório de Ficologia, Departamento de Ciências Biológicas, Universidade Estadual de Feira de Santana, Av. Transnordestina s/n, Bairro Novo Horizonte, 44036-900, Feira de Santana, Bahia, Brasil.

${ }^{2}$ Núcleo em Ecologia e Desenvolvimento Socioambiental de Macaé (NUPEM), Universidade Federal do Rio de Janeiro, Campus Macaé, C.P. 119331, 27910-970, Macaé, Rio de Janeiro, Brasil.

Resumo - É apresentado o levantamento de Siphonocladaceae da Bahia, Brasil, como contribuição ao conhecimento das clorofíceas do litoral do Estado. São reconhecidos quatro gêneros e cinco espécies: Chamaedoris peniculum, Dictyosphaeria cavernosa, D. versluysii, Ernodesmis verticillata e Siphonocladus tropicus. É apresentada chave de identificação para as espécies, além de descrições, ilustrações, comentários e mapas de distribuição geográfica na Bahia. Palavras-chave adicionais: Brasil, Chamaedoris, Chlorophyta, Dictyosphaeria, Ernodesmis, Nordeste, Siphonocladus.

\begin{abstract}
Flora of Bahia: Siphonocladaceae) - A survey of Siphonocladaceae of Bahia State, Brazil, is presented as a contribution to the knowledge of the coastal chlorophytes. Four genera and five species are recognized: Chamaedoris peniculum, Dictyosphaeria cavernosa, D. versluysii, Ernodesmis verticillata and Siphonocladus tropicus. A key to species, descriptions, illustrations, comments and distribution maps from the State are presented.
\end{abstract}

Additional key words: Chamaedoris, Chlorophyta, Dictyosphaeria, Ernodesmis, Northeast Brazil, Siphonocladus.

\section{Siphonocladaceae}

Talo constituído por única célula multinucleada, quando jovem, e multicelular multinucleado, quando adulto. Fixo ao substrato por rizoides ramificados, hapteroidais. Numerosos cloroplastos formando uma rede parietal ou camada mais ou menos contínua; pirenoides presentes. Reprodução assexuada por zoósporos biflagelados. Fragmentação comum em alguns gêneros. Histórico de vida haplodiplonte, gerações isomórficas; gametófito produzindo isogametas biflagelados; esporófito produzindo meiósporos tetraflagelados, zoósporos bi- ou tetraflagelados.

Siphonocladaceae inclui 10 gêneros e 29 espécies distribuídas nos oceanos Atlântico, Índico e Pacífico (Guiry \& Guiry 2012). Para o Atlântico Americano, são registrados cinco gêneros e oito espécies (Wynne 2011). No litoral do Brasil e da Bahia, é representada por quatro gêneros e cinco espécies (Moura et al. 2012).

\section{Chave de identificação}

1'. Talo globoso, não ramificado.

2. Dictyosphaeria

2. Talos sólidos, polistromáticos, projeções espiniformes presentes 2.2.D. versluysii

2'. Talos ocos, monostromáticos, projeções espiniformes ausentes. 2.1. D. cavernosa

1. Talo filamentoso ramificado.

3. Ramificação verticilada, ramos clavados, originados no ápice das células.... 3.1. Ernodesmis verticillata

3'. Ramificação irregular, unilateral a subdicotômica, em um ou vários planos.

*Autora para correspondência: aigarama@yahoo.com.br

Editor responsável: Alessandro Rapini

Submetido em: 16 maio 2012; publicação eletrônica: 21 dez. 2012
4. Estipe com constrições anelares em toda a sua extensão; filamentos unisseriados originados no ápice do estipe, com ramificação em um único plano, unilateral a subdicotômica, unidos por células tenaculares formando capítulo.

1.1.Chamaedoris peniculum

4'. Célula basal com constrições apenas na porção basal, células ramificadas em vários planos formando talo multisseriado; ausência de células tenaculares e capítulo.

4.1. Siphonocladus tropicus

\section{Chamaedoris Mont.}

Talo ereto, estipitado, fixo ao substrato por rizoides ramificados originados por divisão intercalar da base do estipe, composto de capítulo apical. Estipe unicelular, levemente calcificado, com constrições anelares em toda a sua extensão, com ou sem pequenas células sobrepostas na extremidade distal, formadas por divisão celular segregativa. Capítulo multicelular não calcificado, auriculado, globoso, subgloboso ou oblongo, originado da extremidade distal do estipe e de células sobrepostas, composto de células filiformes, ramificação unilateral a irregular, dicotômica a subdicotômica, capítulo estruturalmente reforçado pelo entrelaçamento de filamentos adjacentes, curvos ou sinuosos, anastomosados uns aos outros através de células tenaculares. Crescimento do estipe por divisão celular segregativa e dos filamentos do capítulo por divisão celular apical e intercalar. Cloroplastos poligonais, unidos formando uma rede parietal, com um pirenoide central. Inclusões cristalinas birrefringentes de oxalato de cálcio e de sílica e proteicas, não birrefringentes, visíveis no protoplasto.

O gênero Chamaedoris é exclusivamente marinho, ocor-

Sitientibus série Ciências Biológicas 12(2): 167-177. 2012. 
rendo em águas tropicais e subtropicais (Guiry \& Guiry 2012). De acordo com Leliaert et al. (2007), três espécies de Chamaedoris são reconhecidas: C. auriculata B $\emptyset$ rgesen, $C$. delphinii (Hariot) J.Feldmann \& Børgesen e C. peniculum (J.Ellis \& Sol.) Kuntze. Destas, apenas $C$. peniculum é registrada para o Atlântico Americano (Wynne 2011), litoral do Brasil e da Bahia (Moura et al. 2012).

1.1. Chamaedoris peniculum (J.Ellis \& Sol.) Kuntze, Revis. Gen. Pl. 3(3): 400. 1898. Corallina peniculum J.Ellis \& Sol., Nat. Hist. Zoophytes: 127. 1786.

Figuras 1 e 2.

Talo verde-claro, $5-8 \mathrm{~cm}$ alt., crescendo solitário ou em grupos de até 10 indivíduos. Estipe cilíndrico, não ramificado, 3,6-5,1-6,5 cm compr. $\times$ 1-2-3 mm diâm., parede celular estratificada, $25-52 \mu \mathrm{m}$ espessura. Capítulo achatado, peltado, , 0,5-1,2-3 cm compr. $\times 0,6-1,85-3,5 \mathrm{~cm}$ diâm., formado por filamentos originados distalmente no estipe e a partir de 1-3 células pequenas, sobrepostas, formadas no ápice do estipe; filamentos capitulares com ramificação unilateral a subdicotômica, até $6^{\mathrm{a}}$ ordem, atraso na formação de septo na base; células basais $250-494-800 \mu \mathrm{m}$ compr. × 140-213-310 $\mu \mathrm{m}$ diâm.; células intermediárias 5501570-3260 $\mu \mathrm{m}$ compr. $\times$ 120-174-240 $\mu \mathrm{m}$ diâm.; células mediano-apicais com intumescimentos; parede celular 2,5$10 \mu \mathrm{m}$ espessura; células apicais $400-1604-4300 \mu \mathrm{m}$ compr. × 100-145-200 $\mu \mathrm{m}$ diâm., ápice arredondado. Inclusões cristalinas de oxalato de cálcio hexagonais a losangos e triangulares no estipe; de sílica, em forma de finas agulhas agrupadas e proteicas tetraédricas e cúbicas, não birrefringentes, nas células do estipe e do capítulo. Células férteis nas porções subapical e apical do capítulo, com papilas laterais e apicais.

Chamaedoris peniculum está amplamente distribuída no Oceano Atlântico, registrada para o mar do Caribe, Colômbia, Venezuela e Brasil (Guiry \& Guiry 2012), ocorrendo no litoral dos estados do Ceará, Rio Grande do Norte, Paraíba, Pernambuco, Alagoas, Bahia, Espírito Santo e Rio de Janeiro (Moura et al. 2012). E/F9, H8/9, I8: região entremarés, sobre substrato rochoso, em local protegido da arrebentação das ondas e no infralitoral, a $35 \mathrm{~m}$ de profundidade. Teve como epífitas Sahlingia subintegra (Rosenv.) Kornmann, Erythrotrichia carnea (Dillwyn) J.Agardh, Ceramium sp., algas calcárias crostosas e cianobactérias. Talos férteis nos meses de março, abril e novembro.

Material selecionado - Caravelas, Abrolhos, $17^{\circ} 05^{\prime} 54^{\prime \prime} \mathrm{S}$, 365'08'W, 14 nov. 1997, Projeto REVIZEE s.n. (RFA 28444); Camaçari, 1258'33,4”'S, 38²2'16,6”W, 17 jan. 2003, EMBASA s.n. (ALCB 60709); Canavieiras, 30 mar. 2007, A.M. Alves et al. s.n. (HUEFS 136590); Ilha de Itaparica, Vera Cruz, Praia da Enseada do Pedrão, 4 jun. 2008, C.W.N. Moura s.n. (HUEFS 136589); Porto Seguro, Arraial d'Ajuda, Praia de Mucugê, 2 nov. 1994, C.W.N. Moura s.n. (HUEFS 136592); Salvador, Praia da Aleluia, 18 abr. 2007, A.M. Alves \& C.S. Santana s.n. (HUEFS 136588); Santa Cruz Cabrália, Arakakaí, 4 nov. 1994, C.W.N. Moura s.n. (HUEFS 136591).

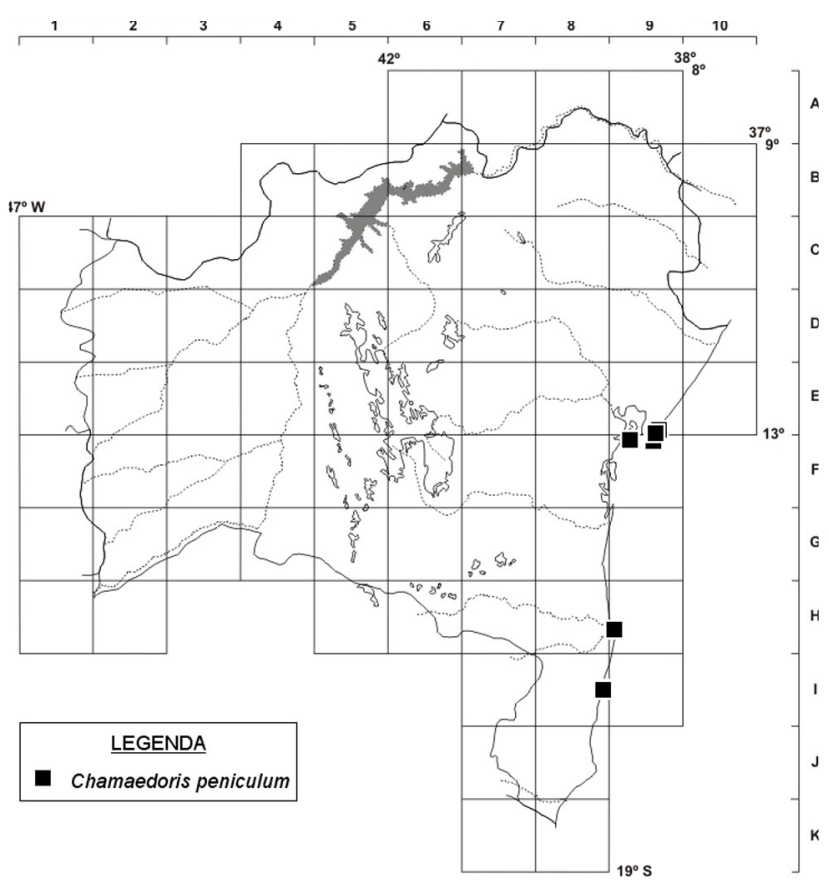

Figura 1. Mapa de distribuição de Chamaedoris peniculum no litoral do estado da Bahia.

\section{Dictyosphaeria Decne.}

Talo multicelular, crescendo solitário ou em grupos, de consistência sólida e rígida ou oca e delicada, com aspecto subesférico a achatado, irregularmente lobado, às vezes colapsado; fixo ao substrato por rizoides hapteroidais originados das células da região basal do talo. Monostromático ou polistromático, composto de células poligonais, unidas por células tenaculares microscópicas simples, bi ou trifurcadas, com extremidade dilatada e crenulada, formadas lateralmente entre células adjacentes. Projeções espiniformes, quando presentes, simples ou bifurcadas, retas ou curvas, na parede celular interna, com crescimento voltado para o centro da célula. Crescimento do talo por divisão celular segregativa, na qual o protoplasma se divide simultaneamente em numerosas agregações multinucleadas de citoplasma, formando esferas com paredes próprias de crescimento endógeno, que se expandem e rompem a parede da célula parental. Cloroplastos laminares, discoides a poligonais, livres ou formando retículo, com vários pirenoides; inclusões cristalinas birrefringentes de oxalato de cálcio, de carbonato de cálcio e de sílica.

Dictyosphaeria é um gênero exclusivamente marinho, com distribuição tropical e subtropical (Guiry \& Guiry 2012). O número de espécies no gênero é controverso; alguns autores, como Egerod (1952) e Womersley (1984), reconheceram 12 espécies, ao passo que Guiry \& Guiry (2012) reconhecem nove e Kraft (2007), apenas seis. Para o Atlântico Americano, são registradas três espécies: $D$. cavernosa (Forssk.) Børgesen, D. ocellata (M.Howe) J.L.Olsen e D. versluysii Weber Bosse (Wynne 2011); a primeira e a última ocorrem na Bahia (Moura et al. 2012). 

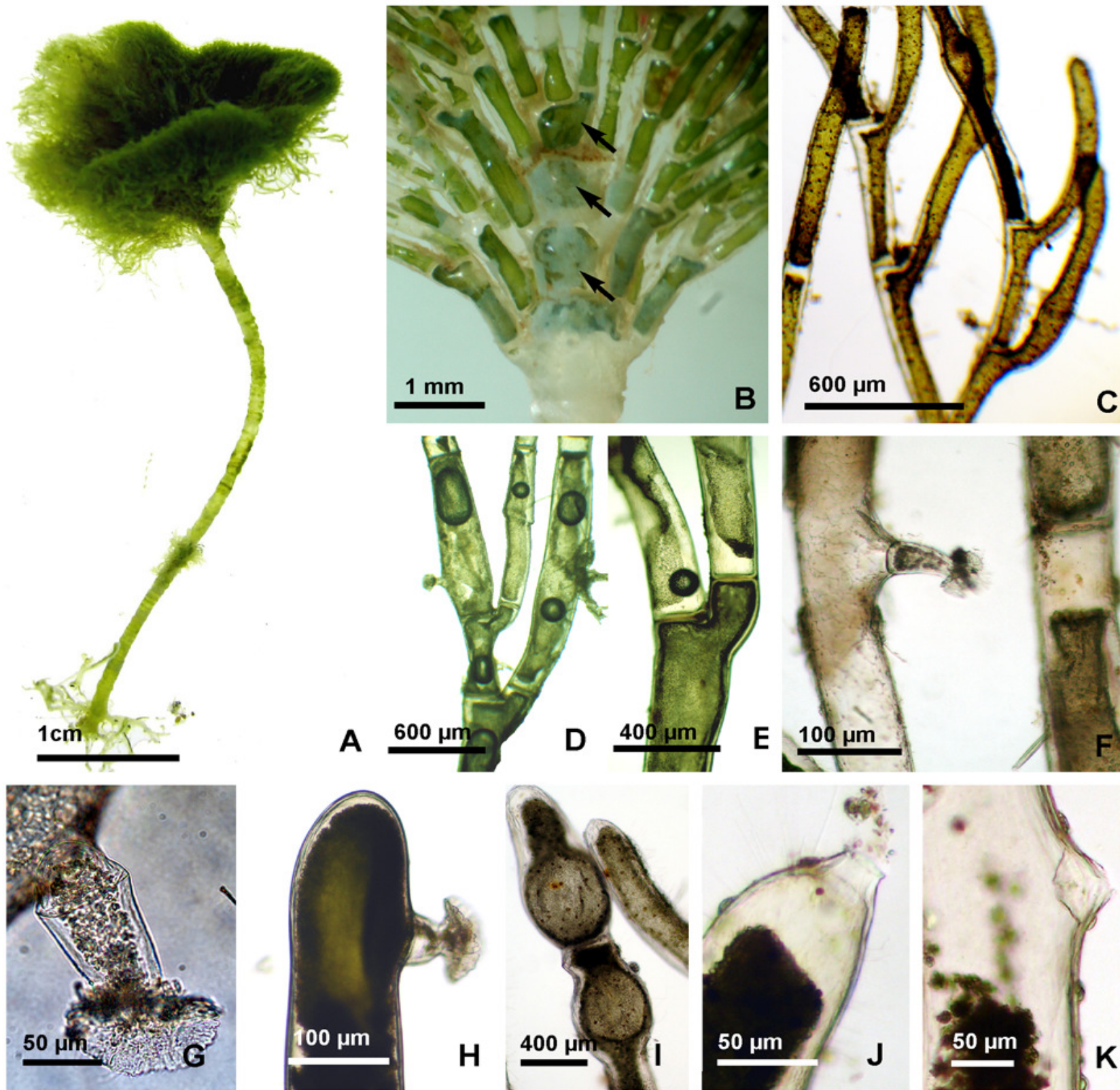

A $600 \mu \mathrm{m}$
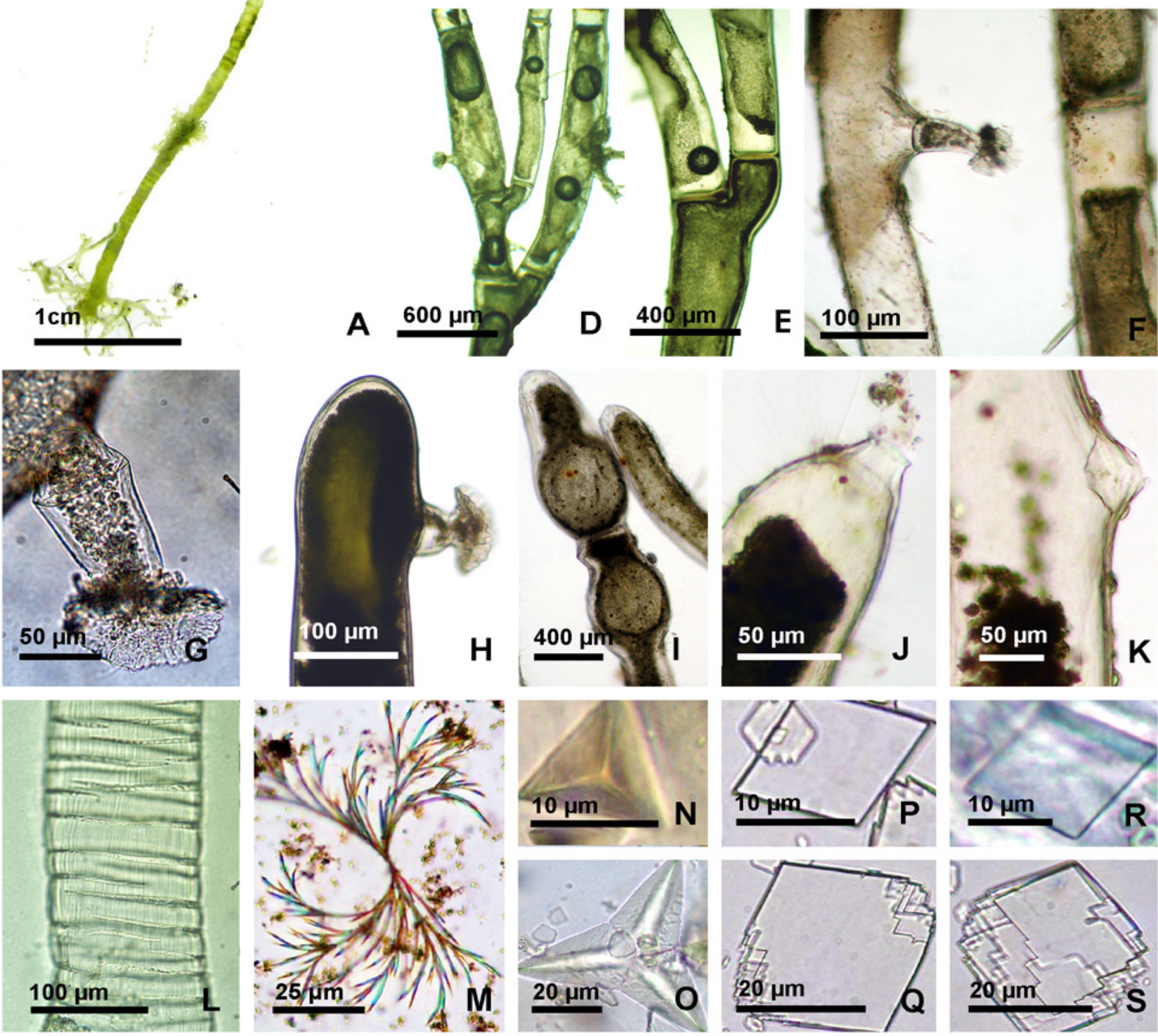

Figura 2. Chamaedoris peniculum: A- aspecto geral; B- detalhe do capítulo com células sobrepostas (setas) C-E- detalhe da ramificação unilateral; FH- detalhe das células tenaculares; I- células intumescidas; J/K- células férteis com papila; L- detalhe da parede celular lamelada do estipe; M- cristais de sílica em forma de finas agulhas agrupadas; N/O- cristais proteicos tetraédricos; P-S- cristais de oxalato de cálcio em forma de hexágonos a losangos e triangular, com margem lisa ou recortada (A- HUEFS 136589; B, C, F, G-K- HUEFS 136588; D, E- RFA 28439; L- HUEFS 136592; M- RFA 28443; N, O- HUEFS 136590; P-S- HUEFS 136591). 


\subsection{Dictyosphaeria cavernosa (Forssk.) Børgesen, Danks}

Botanisk Arkiv 8(2): 2. 1932. Ulva cavernosa Forssk., Havniae: 187. 1775.

Figuras 3 e 4.

Talo verde-escuro, oco, subesférico a alongado, irregularmente lobado, ca. $1,7 \mathrm{~cm}$ compr. $\times$ ca. 5,2 cm diâm., delicado, monostromático, constituído de células poligonais com 680-1151-1640 um diâm., unidas por fileiras de células tenaculares, com extremidade dilatada e crenulada, simples e bifurcadas, dispostas alternadamente. Projeções espiniformes ausentes. Inclusões cristalinas e estruturas reprodutivas não observadas.

Dictyosphaeria cavernosa é amplamente distribuída nos oceanos Atlântico, Índico e Pacífico (Guiry \& Guiry 2012). No Brasil, é registrada para os estados do Ceará, Paraíba, Pernambuco, Bahia, Espírito Santo e Rio de Janeiro (Moura et al. 2012). E/F9, I/J8: em arribada.

Material selecionado - Caravelas, Abrolhos, $19^{\circ} 48^{\prime} 01^{\prime \prime} \mathrm{S}$ 3746'22”'W, 16 nov. 1997, Projeto REVIZEE s.n. (RFA 28460); Ilha de Itaparica, Vera Cruz, Mar Grande, 9 abr. 1952, E. Nonato s.n. (SPF 4411, SPF 23); Prado, Praia da Barra do Caí, 14 jun. 2007, A.M. Alves \& C.S. Santana s.n. (HUEFS 136331); Salvador, Praia de Itapuã, 5 nov. 1964, A.B. Joly \& Y. Ugadim s.n. (SP 317563); ib., Ilha de Maré, Praia do Botelho, 27 set. 1999, M.B. Barros-Barreto et al. s.n. (RB 347131).

Essa espécie é subcoletada no litoral baiano, possivelmente pela carência de coletas em infralitoral, tendo sido encontrada apenas uma vez durante este trabalho. Segundo Littler \& Littler (2000), D. cavernosa cresce fixa a substratos rochosos formando densos tapetes em águas eutróficas, até $40 \mathrm{~m}$ de profundidade. Através de análises de material de herbários brasileiros verificou-se que esta espécie foi registrada ocorrendo em profundidades de até $57 \mathrm{~m}$ no litoral do Brasil.

\subsection{Dictyosphaeria versluysii Weber Bosse, Nuova Notarisia}

16: 144.1905 ('versluysi').

Figuras 5 e 6.

Talo verde-escuro, sólido, extremamente rígido, subesférico a achatado, 0,3-4,5 cm compr. $\times 0,3-2,25-12,6$ $\mathrm{cm}$ diâm., polistromático, solitário ou em densas aglomerações, constituído de células primárias poligonais de 200 1055-1800 $\mu \mathrm{m}$ diâm., unidas por fileiras de células tenaculares, com extremidade dilatada e crenulada, bifurcadas e trifurcadas, com disposição alterna. Projeções espiniformes simples, retas ou curvas, nas paredes internas das células, crescendo em direção ao centro da célula. Inclusões cristalinas birrefringentes de três tipos: 1- cristais de sílica, em forma de finas agulhas agrupadas, 2- de oxalato de cálcio, em forma de octaedros e de estruturas elípticas alongadas, simples ou agrupadas em cruz ou em agregados em forma de estrelas, e 3- de carbonato de cálcio, em forma de cones formando agregados globosos, visíveis no protoplasto das células. Estruturas reprodutivas não observadas.

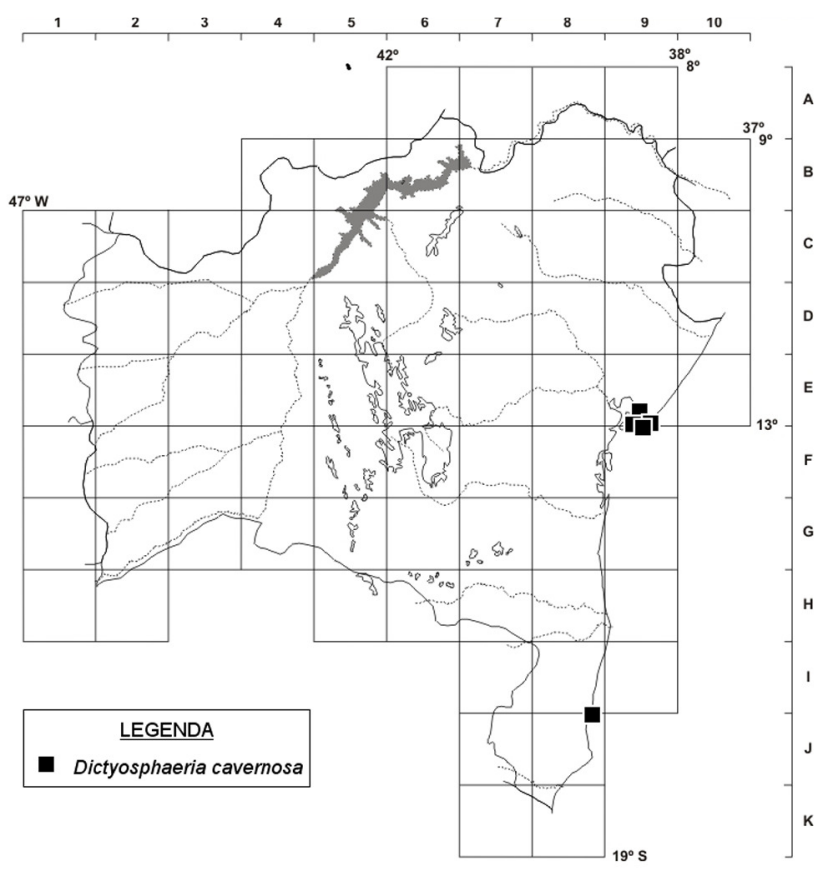

Figura 3. Mapa de distribuição de Dictyosphaeria cavernosa no litoral do estado da Bahia.

Dictyosphaeria versluysii ocorre nos oceanos Atlântico, Índico e Pacífico (Guiry \& Guiry 2012). No litoral brasileiro, é registrada para os estados do Rio Grande do Norte, Paraíba, Pernambuco, Bahia, Alagoas e Espírito Santo (Moura et al. 2012). E9, E10, E/F9, F9, G8/9, G/H8/9, I8/ 9, I/J8: comum na área estudada, na região entremarés, isolada ou em aglomerados, tanto em locais protegidos quanto batidos e sob a arrebentação das ondas, onde os talos são menores. Teve como epífitas Anadyomene stellata (Wulfen) C.Agardh, Gelidiella acerosa (Forssk.) Feldmann \& Hamel, Sahlingia subintegra, Hypnea musciformis (Wulfen) J.V.Lamour., Amphiroa fragilissima (L.) J.V.Lamour. e A. anastomosans Weber Bosse.

Material selecionado - Cairu, Ilha de Tinharé, Morro de São Paulo, Terceira Praia, 3 maio 2003, C.W.N. Moura et al. s.n. (HUEFS 136633); Camaçari, Arembepe, Praia de Piruí, 17 fev. 2007, A.M. Alves \& C.S. Santana s.n. (HUEFS 136335); Entre Rios, Subaúma, 19 abr. 2007, A.M. Alves \& C.S. Santana s.n. (HUEFS 136332); Ilha de Itaparica, Itaparica, Praia de Manguinhos, 5 mar. 1973, A.G. Pedrini s.n. (RB 163383), como D. vanbosseae Børgesen; ib, Vera Cruz, Praia da Penha, 18 mar. 2007, C.W.N. Moura et al. s.n. (HUEFS 136350); Ilhéus, Praia do Aeroporto, 8 set. 2006, A.M. Alves et al. s.n. (HUEFS 136366); Itacaré, Praia da Concha, 9 set. 2006, A.M. Alves et al. s.n. (HUEFS 136368); Mata de São João, Praia do Forte, 11 ago. 2006, A.M. Alves \& C.S. Santana s.n. (HUEFS 136334); Salvador, Praia da Barra, 10 ago. 2006, A.M. Alves s.n. (HUEFS 136344); ib., Ilha dos Frades, Praia de Paramana, 5 dez. 2000, G.M. Amado Filho et al. s.n. (RB 359916); Santa Cruz Cabrália, Arakakaí, 15 abr. 2002, C.W.N. Moura s.n. (HUEFS 136370); Prado, Corumbau, 15 jun. 2007, A.M. Alves \& C.S. Santana s.n. (HUEFS 136376); Porto Seguro, Arraial d'Ajuda, Praia de Mucugê, 13 jul. 2006, C.W.N. Moura et al. s.n. (HUEFS 136374). 


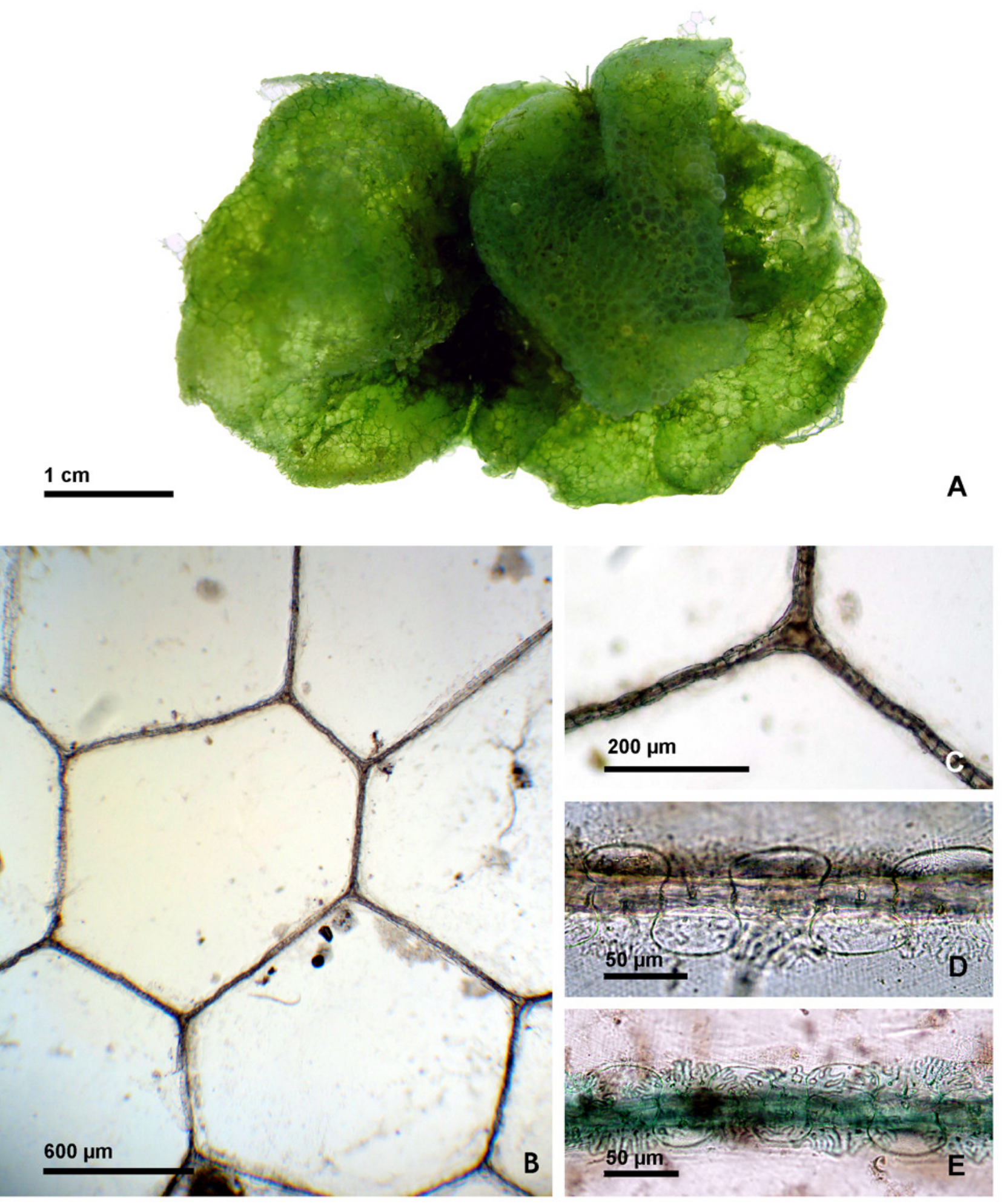

Figura 4. Dictyosphaeria cavernosa: A- aspecto geral do talo; B- vista superficial das células hexagonais irregulares; C- zona de contato das paredes celulares; D/E- detalhe da zona de contato, mostrando células tenaculares unindo células adjacentes (HUEFS 136331). 

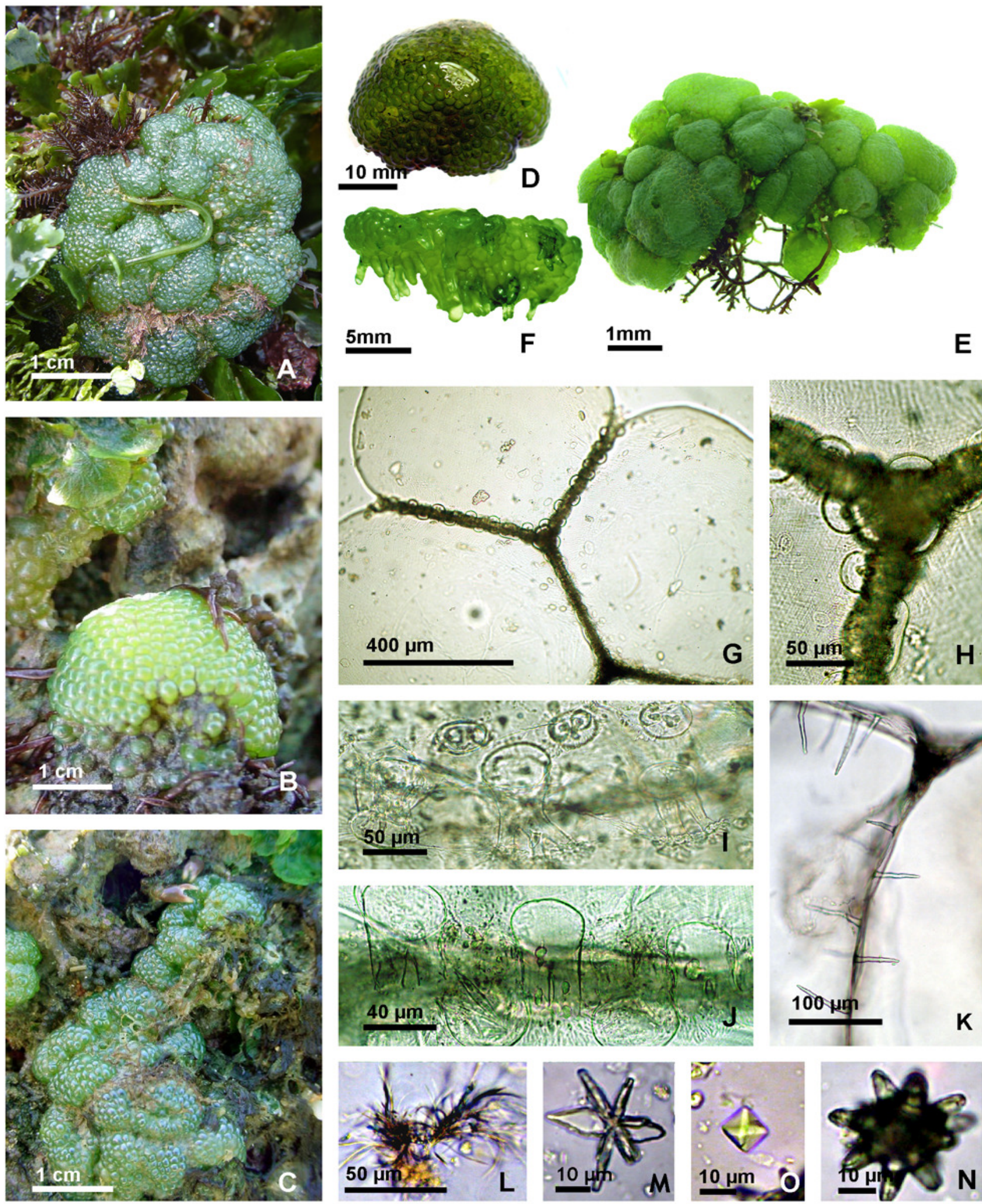

Figura 5. Dictyosphaeria versluysii: A-C- hábito; D/E- aspecto geral; F- detalhe do talo com rizoides basais; G- corte transversal do talo, mostrando células arredondadas unidas por células tenaculares; H- zona de contato das paredes celulares com células tenaculares. I/J- detalhe das células tenaculares, com base crenulada, bifurcadas e trifurcadas; K- projeções espiniformes simples; L- cristais de sílica em forma de finas agulhas agrupadas; $\mathbf{M} / \mathbf{N}$ cristais de oxalato de cálcio (M- cristais em forma de estruturas elípticas alongadas, agrupadas em forma de estrelas; $\mathrm{N}$ - cristais de carbonato de cálcio em forma de cones formando agregados globosos; O- cristais em forma de octaedros). (A, C, G-J- HUEFS 136335; B- HUEFS 136346; D- HUEFS 136355; E, O- HUEFS 136353; F- HUEFS 136356; K- HUEFS 136359; L- HUEFS 136375; M, N- HUEFS 136372).

Sitientibus série Ciências Biológicas 12(2): 167-177. 2012. 


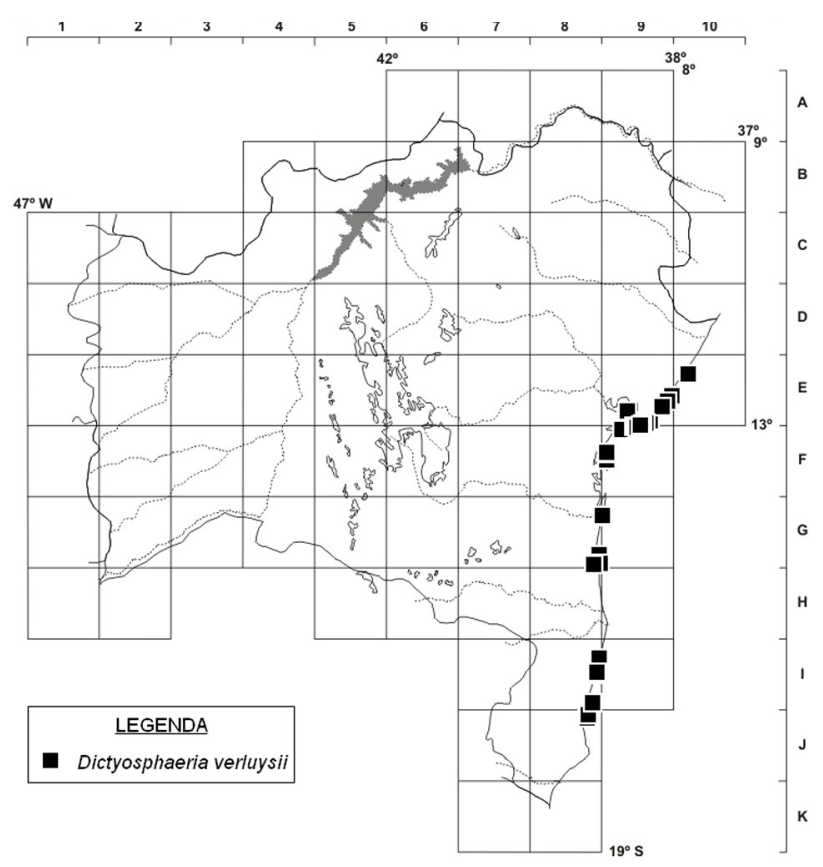

Figura 6. Mapa de distribuição de Dictyosphaeria versluysii no litoral do estado da Bahia.

\section{Ernodesmis Børgesen}

Talo ereto, vesiculoso, ramificado, formando almofadas laxas a densas, de contorno esférico, fixo ao substrato por rizoides ramificados, septados, originados por invaginação centrípeta da parede da célula basal do talo. Célula basal macroscópica, clavada, com constrições anelares na porção basal, originando distalmente várias célulasfilhas (3-18) de tamanho variável, semelhantes à célula parental, dispostas em verticilos ou, às vezes, com disposição irregular; células-filhas apresentando o mesmo padrão de ramificação, até $6^{a}$ ordem. Células tenaculares presentes na junção entre a célula-mãe e as células-filhas. Crescimento do talo por divisão celular lenticular, ocasionalmente por divisão celular segregativa modificada, na qual as massas citoplasmáticas formadas, após secretarem novas paredes celulares, são liberadas da célula parental, desenvolvendose em novos talos. Novos talos podendo ser formados a partir de rizoides de talos velhos. Cloroplastos pequenos, poligonais, unidos pelas extremidades, formando uma rede parietal, um pirenoide por cloroplasto; inclusões cristalinas birrefringentes de sílica, em forma de finas agulhas agrupadas, presentes no protoplasto.

O gênero monoespecífico Ernodesmis é exclusivamente marinho sendo comumente encontrado no Oceano Atlântico, com registros para os oceanos Pacífico Tropical e Índico (Guiry \& Guiry 2012), ocorrendo sobre recife de coral e substrato arenoso.

3.1. Ernodesmis verticillata (Kütz.) Børgesen, Bot. Tidsskr. 32: 259; figs 10-12. 1912. Valonia verticillata Kütz., Bot. Zeitung (Berlin) 5: 165. 1847.

Figuras 7 e 8.
Talo verde-claro a amarelo-translúcido, ereto, até $3 \mathrm{~cm}$ alt., solitário ou formando densas agregações, fixo ao substrato por rizoides ramificados e septados. Célula basal clavada, com constrições anelares na base, 3-5-6 mm compr. $\times 280-438-540 \mu \mathrm{m}$ diâm. na base, $1280-1420-1560 \mu \mathrm{m}$ diâm. no ápice, portando 4-7-11 células na região apical, dispostas em verticilos ou, às vezes, irregulares, originados na porção mediana da célula, 2-4-5 mm compr. × 260-337$460 \mu \mathrm{m}$ diâm., até $6^{\mathrm{a}}$ ordem, morfologia e ramificação semelhantes à célula parental. Células tenaculares presentes na junção entre a célula-mãe e as células-filhas. Inclusões cristalinas birrefringentes de sílica, em forma de finas agulhas agrupadas, presentes no protoplasto. Células férteis com conteúdo protoplasmático dividido, com papilas laterais para liberação das estruturas reprodutivas.

No litoral do Brasil, é registrada para os estados do Ceará, Paraíba, Pernambuco, Rio de Janeiro, São Paulo e Santa Catarina (Moura et al. 2012). Na Bahia, foi registrada pela primeira vez por Alves et al. (2010). E9, E/F9: sobre substrato rochoso, em locais protegidos do sol e da arrebentação das ondas, solitárias ou formando densos agregados. Talos férteis observados em março.

Material selecionado - Itha de Itaparica, Vera Cruz, Praia da Conceição, 7 maio 2008, A.M. Alves et al. s.n. (HUEFS 136661); Madre de Deus, Praia de Suape, 30 jan. 2010, A.M. Alves (HUEFS 155597).

Talos com algumas células apresentando massas citoplasmáticas de formato irregular, formadas por divisão celular segregativa modificada, foram observadas no material estudado. Estas massas também foram observadas por Børgesen (1913, 1940), Papenfuss \& Chihara (1975) e Kanagawa (1984). Diferentemente do que ocorre em Siphonocladus e Dictyosphaeria, apenas parte do protoplasto das células sofre divisão celular segregativa. É rara na área de estudo, sendo, até o presente, encontrada apenas nas ilhas de Itaparica e Madre de Deus (Baía de Todos os Santos). Teve como epífita H. musciformis.

\section{Siphonocladus F.Schmitz}

Talo ramificado, crescendo em tufos eretos ou prostrados, constituído por célula basal curta a longa, às vezes indistinta, subcilíndrica a clavada, com ou sem constrições anelares na base; fixo ao substrato por rizoides multicelulares formados por invaginação centrípeta na porção basal. Eixo principal inicialmente constituído por célula basal grande, ramificando-se por divisão celular segregativa. Células-filhas, sem septo na base, por sua vez divididas de maneira similar, formando células precedentes menores, até $4^{\mathrm{a}}$ ordem. Ramificação irregular, unilateral ou em vários planos. Eixo secundário às vezes constituído por duas a três fileiras irregulares de células. Células tenaculares presentes em algumas espécies para reforço estrutural do talo. Células multinucleadas, com numerosos cloroplastos poligonais, livres ou formando um retículo, com pirenoides bilenticulares. Inclusões cristalinas birrefringentes de oxalato de cálcio, 

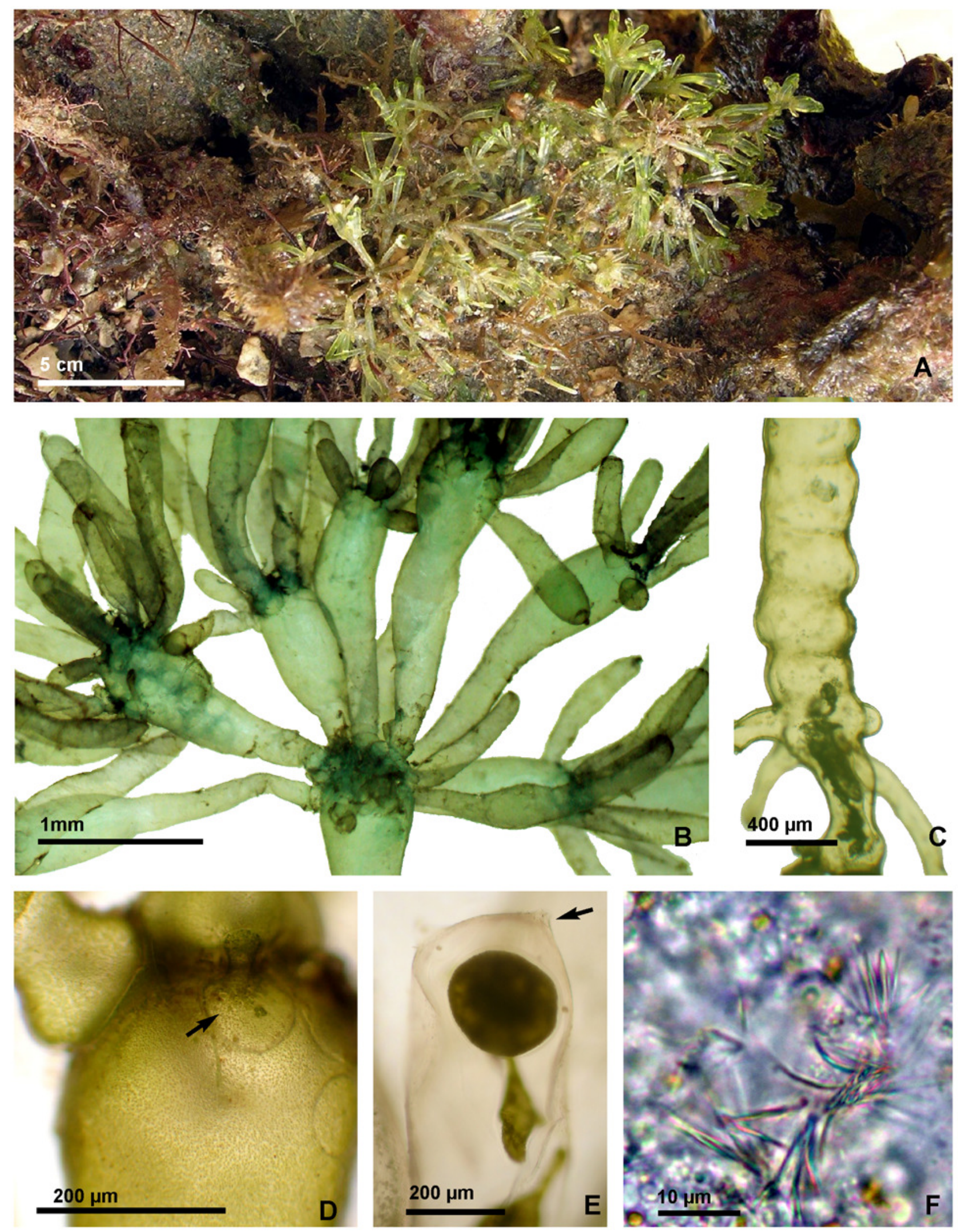

Figura 7. Ernodesmis verticillata: A- hábito; B- padrão de ramificação verticilada; C- célula basal com constrições anelares; D- detalhe das células tenaculares (seta); E- célula apical fértil, com papila e massa citoplasmática formada por divisão celular segregativa modificada; $\mathbf{F}$ - cristais de sílica em forma de finas agulhas agrupadas (A- HUEFS 136661; B, C- HUEFS 136656; D- HUEFS 136660; E, F- HUEFS 136662). 


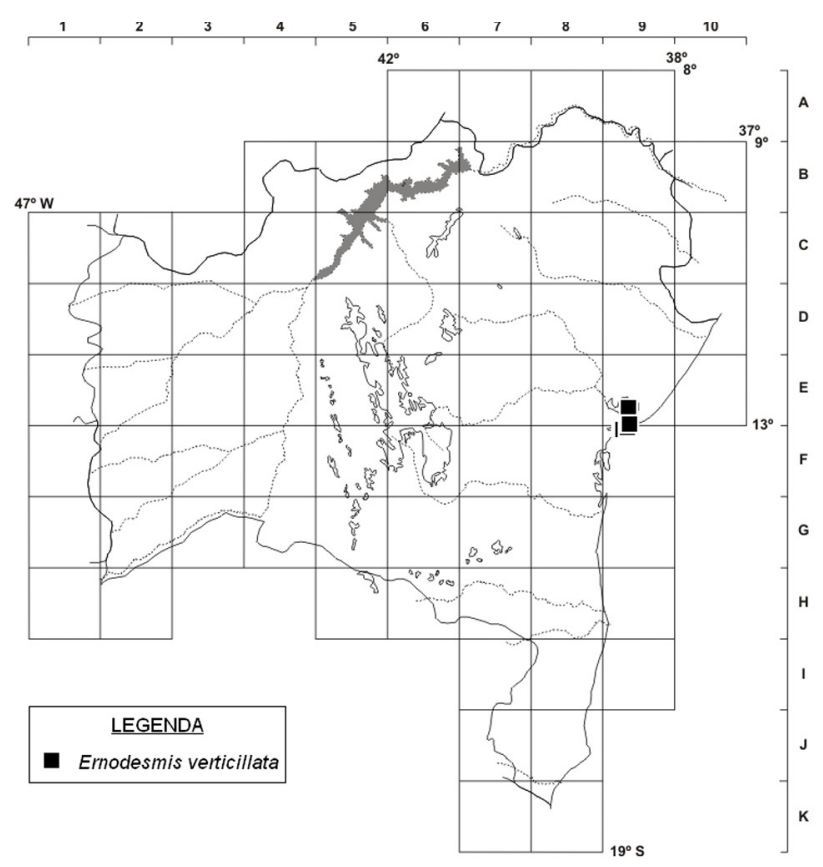

Figura 8. Mapa de distribuição de Ernodesmis verticillata no litoral do estado da Bahia.

em forma de hexágonos e de octaedros, e cristais de sílica, em forma de finas agulhas agrupadas, presentes no protoplasto.

O gênero é exclusivamente marinho ocorrendo em águas temperadas e tropicais dos oceanos Atlântico, Índico e Pacífico (Guiry \& Guiry 2012). Inclui oito espécies (Guiry \& Guiry 2012), das quais S. rigidus M.A.Howe e S. tropicus são referidas para o Atlântico Americano, incluindo o Brasil (Joly et al. 1976; Wynne 2011). Para o litoral da Bahia, foi registrada apenas S. tropicus (Nunes et al. 2005).

\subsection{Siphonocladus tropicus (P.Crouan \& H.Crouan)}

J.Agardh, Acta Univ. Lund. 23(2): 105. 1887. Apjohnia tropica P.Crouan \& H.Crouan in Schramm \& Mazé, Essai Class. des algues Guadel.: 47. 1865. Figuras 9 e 10.

Talo verde-claro, ereto, $1,5-4,5 \mathrm{~cm}$ alt., consistência áspera, solitário ou em grupo, fixo ao substrato por filamentos rizoidais ramificados e septados. Célula basal longa, clavada, com constrições anelares na base, $0,1-0,54-1,3 \mathrm{~cm}$ compr. × 168-426-900 $\mu \mathrm{m}$ diâm., ramificação em vários planos, até $4^{\mathrm{a}}$ ordem, ramos asseptados, morfologia e estrutura semelhantes à célula-mãe. Células $0,1-0,8-2,5 \mathrm{~cm}$ compr. $\times 60-260-740 \mu \mathrm{m}$ diâm., parede celular fina; célula apical com ápice arredondado. Células tenaculares e inclusões cristalinas não observadas. Células férteis com papilas laterais para liberação das estruturas reprodutivas.

No litoral do Brasil, a espécie é registrada nos estados do Maranhão, Paraíba, Pernambuco, Bahia e Espírito Santo. E9, E/F9, I8: sobre substrato rochoso, em locais protegidos, como epífita de Digenea simplex (Wulfen) C.Agardh e em arribada. Talos férteis encontrados em setembro.

Material selecionado - Camaçari, Itacimirim, Praia da Espera, 19 fev. 2007, A.M. Alves \& C.S. Santana s.n. (HUEFS 136619); Ilha de Itaparica, Vera Cruz, Praia da Enseada do Pedrão, 27 set. 2007, C.W.N. Moura et al. s.n. (HUEFS 136622); Porto Seguro, Arraial d'Ajuda, Praia de Mucugê, 13 jul. 2006, C.W.N. Moura et al. s.n. (HUEFS 136624).

Siphonocladus tropicus é uma espécie de fácil identificação, com morfologia geral estável, não apresentando polimorfismo. Segundo Egerod (1952), o talo em tufos é característico da espécie. Nunes et al. (2005) registraram-na para o litoral da Bahia, a $23 \mathrm{~m}$ de profundidade, porém não forneceram descrição nem ilustração do material. Esta é a primeira vez que talos férteis de S. tropicus estão sendo descritos e ilustrados para o litoral brasileiro. É pouco comum na área estudada e teve como epífita Asteronema breviarticulatum (J.Agardh) Ouriques \& Bouzon.

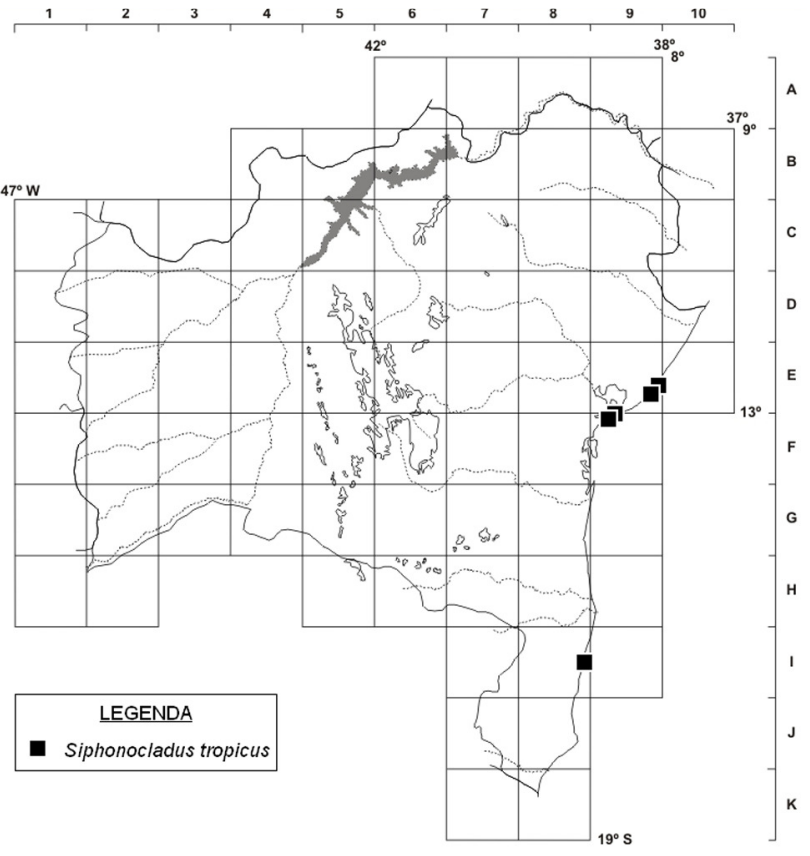

Figura 9. Mapa de distribuição de Siphonocladus tropicus no litoral do estado da Bahia.

\section{Agradecimentos}

Este trabalho é parte da dissertação de mestrado da primeira autora, desenvolvida no Programa de Pós-graduação em Botânica da UEFS, a qual agradece à CAPES pela concessão da bolsa de mestrado. Os autores agradecem à FAPESB pelo financiamento parcial do trabalho (Proc. PPP 0011/2006), à UEFS (Projeto Flora da Bahia) e aos curadores dos herbários visitados pela facilidade de acesso ao material. 

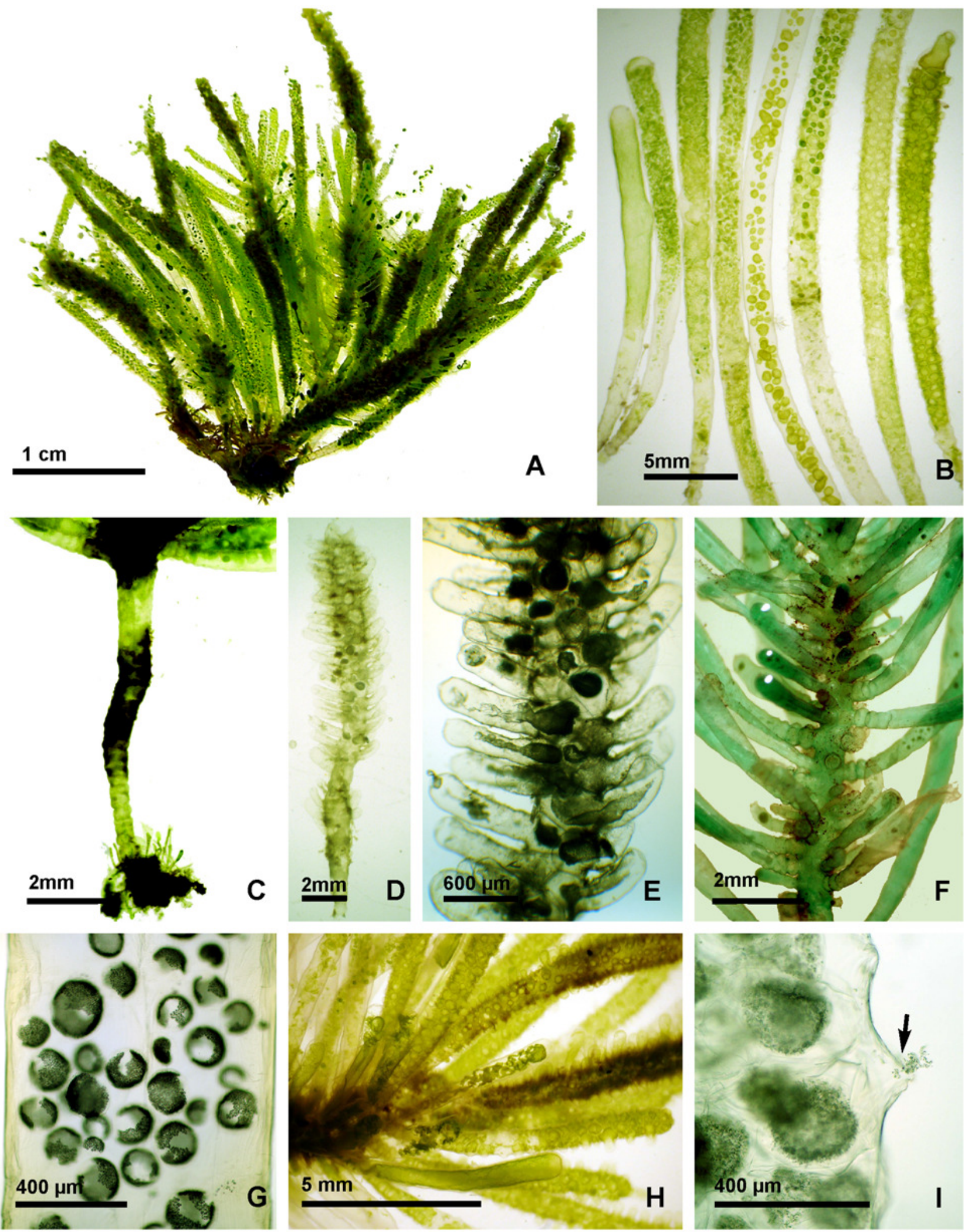

Figura 10. Siphonocladus tropicus: A- aspecto geral; B- cenócitos em processo de divisão celular segregativa; C- estipe com constrições anelares; D/E, H- talo com ramificação em vários planos; F- detalhe dos ramos secundários om constrições anelares na base; G- detalhe de massas citoplasmáticas formadas por divisão celular segregativa; I- célula fértil com papila (seta) (A, B, H- HUEFS 136619; C- HUEFS 136621; D, E, G, I - HUEFS 136622; FHUEFS 136623). 


\section{REFERÊNCIAS}

Alves, A.M.; Gestinari, L.M.S. \& Moura, C.W.N. 2010. La família Valoniaceae (Chlorophyta) en el estado de Bahía, Brasil: aspectos morfológicos y de distribución. Hidrobiológica 20: 171-184.

Børgesen, F. 1913. The marine algae of the Danish West Indies. 1. Chlorophyceae. Dansk Botanisk Arkiv 1(4): 1-158.

Børgesen, F. 1940. Some marine algae from Mauritius. I. Chlorophyceae. Kongelige Danske Videnskabernes Selskab, Biologiske Meddelelser 15(4): 1-81.

Egerod, L.E. 1952. An analysis of the Siphonous Chlorophycophyta with special reference to the Siphonocladales, Siphonales, and Dasycladales of Hawaii. University of California Publications in Botany 25: 327-367.

Guiry, M.D. \& Guiry, G.M. 2012. AlgaeBase. World-wide electronic publication, National University of Ireland, Galway. Disponível em http://www.algaebase.org; acesso em 3 maio 2012.

Joly, A.B.; Sazima, M. \& Semir, J. 1976. Brazilian deep water marine algae. Additions to the Brazilain flora IV. Boletim de Botânica da Universidade de São Paulo 4: 121-128.

Kanagawa, A.I. 1984. Clorofíceas Marinhas Bentônicas do Estado da Paraíba - Brasil. Tese de Doutorado. Universidade de São Paulo.

Kraft, G.T. 2007. Algae of Australia. Marine benthic algae of Lord
Howe Island and the southern Great Barrier Reef. 1. Green algae. Australian Biological Resources Study \& CSIRO Publishing, Canberra \& Melbourne.

Leliaert, F.; Millar,A.J.K.; Vlaeminck, C. \& Coppejans, E. 2007. Systematics of the green macroalgal genus Chamaedoris Montagne (Siphonocladales), with an emended description of the genus Struvea Sonder. Phycologia 46: 709-725.

Moura, C.W.N.; Branco, C.Z.; Peres C.K. \& Fajar, A. 2012. Ulvophyceae. In: Lista de Espécies da Flora do Brasil. Jardim Botânico do Rio de Janeiro. Disponível em http:// floradobrasil.jbrj.gov.br/2012/FB099035; acesso em 18 dez. 2012.

Nunes, J.M.C.; Santos, A.C.C. \& Santana, L.C. 2005. Novas ocorrências de algas marinhas bentônicas para o estado da Bahia, Brasil. Iheringia, série Botânica 60(1): 99-106.

Papenfuss, G.F. \& Chihara, M. 1975. The morphology and systematic position of the green algae Ernodesmis and Apjohnia. Phycologia 14: 309-316.

Womersley, H.B.S. 1984. The Marine Benthic Flora of Southern Australia. Part I. Government Printer, South Australia, Adelaide.

Wynne, M.J. 2011. A checklist of benthic marine algae of the tropical and subtropical western Atlantic: third revision. Nova Hedwigia Beihefte 140: 1-166.

\section{Lista de Exsicatas}

Alves, A.M. s.n. HUEFS: 136331 (2.1), 136332, 136334, 136335, 136337, 136338, 136339, 136340, 136341, 136343, 136344, 136366, 136367, 136368, 136369, 136375, 136376, 136377, 136379 (2.2), 136588, 136590 (1.1), 136619, 136620 (4.1), 136656, 136657, 136658, 136659, 136660, 136661, 136662, 155597 (3.1); Amado Filho, G.M. s.n. RB 359916, 364873 (2.2); Alves, C.J. s.n. ALCB: 22127 (1.1); Barros-Barreto, M.B. s.n. RB 347131 (2.1); Bastos, G.B. s.n. ALCB: 17249 (1.1); Boccanera, N.B. s.n. ALCB: 17429 (1.1); Borges, G.P. s.n. ALCB: 17250 (1.1), 17251, 17252 (2.2); Borges-Bastos, G. s.n. ALCB: 17397 (1.1); Cetrel s.n. ALCB: 57724, 57725 (4.1), 60613 (1.1); Costa Júnior, O.S. s.n. ALCB: 34873 (2.2); Embasa s.n. ALCB 60709 (1.1); Joly, A.B. s.n. SP: 317562, 317563 (2.1); Luz, D.S. s.n. ALCB: 17466 (2.2); Martins, D.V. s.n. ALCB: 17029 (1.1), 17031 (2.2),
49340 (1.1); Moura, C.W.N. s.n. HUEFS: 136333, 136336, 136345, 136346, 136347, 136348, 136349, 136350, 136351, 136352, 136353, 136354, 136355, 136356, 136357, 136358, 136359, 136360, 136361, 136362, 136363, 136364, 136365, 136370, 136371, 136372, 136373, 136374, 136378 (2.2), 136589, 136591, 136592 (1.1), 136621, 136622, 136623, 136624 (4.1), 136633 (2.2), 136663, 136664 (3.1); Nonato, E. s.n. SPF: 23, 4410, 4411, 317577 (2.1); Nunes, A.P. s.n. ALCB: 17190, 17191 (2.2); Nunes, J.M.C. s.n. ALCB: 17396, 22188, 49137, 49239, 49455, 52949, 52987, 53196 (2.2), 60729 (1.1); Pedrini, A.G. s.n. RB 163383 (2.2); Projeto REVIZEE s.n. RFA: 28439, 28440, 28441, 28442, 28443, 28444, 28445, 28456, 28807 (1.1), 28459, 28460 (2.1). 